\title{
QUEEN'S
UNIVERSITY
BELFAST
}

\section{Received Signal Characteristics of the Indoor Off-Body Communications Channel at $5.8 \mathrm{GHz}$}

Cotton, S. L., \& Scanlon, W. G. (2013). Received Signal Characteristics of the Indoor Off-Body Communications Channel at $5.8 \mathrm{GHz}$. In Proceedings of the 2013 IEEE Antennas and Propagation Society International Symposium (APSURSI) (pp. 1952-1953). Institute of Electrical and Electronics Engineers Inc.. https://doi.org/10.1109/APS.2013.6711634

Published in:

Proceedings of the 2013 IEEE Antennas and Propagation Society International Symposium (APSURSI)

Document Version:

Peer reviewed version

Queen's University Belfast - Research Portal:

Link to publication record in Queen's University Belfast Research Portal

\section{Publisher rights}

(C) 2015 IEEE. Personal use of this material is permitted. Permission from IEEE must be obtained for all other uses, in any current or future media, including reprinting/republishing this material for advertising or promotional purposes, creating new collective works, for resale or redistribution to servers or lists, or reuse of any copyrighted component of this work in other works.

\section{General rights}

Copyright for the publications made accessible via the Queen's University Belfast Research Portal is retained by the author(s) and / or other copyright owners and it is a condition of accessing these publications that users recognise and abide by the legal requirements associated with these rights.

Take down policy

The Research Portal is Queen's institutional repository that provides access to Queen's research output. Every effort has been made to ensure that content in the Research Portal does not infringe any person's rights, or applicable UK laws. If you discover content in the Research Portal that you believe breaches copyright or violates any law, please contact openaccess@qub.ac.uk. 


\section{Received Signal Characteristics of the Indoor Off- Body Communications Channel at $5.8 \mathrm{GHz}$}

\author{
Simon L. Cotton \\ ECIT Institute, \\ Queen's University Belfast, \\ Belfast BT3 9DT, United Kingdom \\ simon.cotton@qub.ac.uk
}

\author{
William G. Scanlon \\ ECIT Institute, \\ Queen's University Belfast, \\ Belfast BT3 9DT, United Kingdom \\ w.scanlon@qub.ac.uk
}

\begin{abstract}
In this paper we investigate the received signal characteristics of a mobile chest-worn transmitter at $5.8 \mathrm{GHz}$ within a high multipath indoor environment. The off-body channel measurements considered both the co- and crosspolarized received signal for both line-of-sight (LOS) and nonLOS (NLOS) conditions. A straightforward channel model based upon the estimated path loss, a lognormal slow fading component and Ricean small-scale fading contribution is developed and used to perform simulations which allow the generation of first order received signal power characteristics.
\end{abstract}

\section{INTRODUCTION}

Increasing competition for spectrum space in the Industrial, Scientific and Medical (ISM) band at $2.45 \mathrm{GHz}$ will force wireless systems designers to consider alternative frequency allocations in other ISM bands with more abundant bandwidth [1]. This issue will be particularly prevalent for users of wireless body and personal area networks where a single person may have a number of discrete wireless nodes attached to their body. Alternative ISM bands with greater bandwidth allocations currently exist at $5.8 \mathrm{GHz}, 24 \mathrm{GHz}$ and $60 \mathrm{GHz}$.

In this paper we consider the $5.8 \mathrm{GHz}$ ISM band for use in indoor off-body communications. Off-body communications are used by wireless devices positioned on the body wishing to communicate with wireless devices in a different physical location. Received signal characteristics of off-body channels have previously been investigated at $868 \mathrm{MHz}$ [2] and $2.45 \mathrm{GHz}$ [3] as well as for multiple-input multiple-output [4] and ultra-wideband [5] communications. In [2], the Nakagami$m$ and Rice fading models were considered for small-scale fading characteristics only with no model specified for slow (shadow) fading or path loss. In this contribution, a simple channel model is presented which incorporates all three of these processes to describe the received signal power for LOS and NLOS conditions, pedestrian traffic and random movements within a high multipath indoor environment.

\section{MEASUREMENT SYSTEM AND EXPERIMENTS}

All of the experiments conducted in this study were carried out at $5.82 \mathrm{GHz}$. The measurement set-up consisted of an ML5805 transceiver chip manufactured by RFMD which was programmed to deliver a continuous wave signal with a power level of $+18 \mathrm{dBm}$. The receiver section of the measurement system was a Rhode and Schwarz ZVB-8 vector network analyser (VNA) configured to collect simultaneous samples of the co- and cross-polarized received signal at a rate of $140 \mathrm{~Hz}$.

The antennas used by both the transmitter and receiver sections of the measurement setup were $+2.3 \mathrm{dBi}$, sleeve dipole antennas (Mobile Mark model PSKN3-24/55S). The horizontal and vertical polarized receive antennas were positioned perpendicular from each other at a height of $1.90 \mathrm{~m}$ from ground level on a polyethylene pole. A vertically polarized antenna was attached at a height of $1.35 \mathrm{~m}$ to the front central chest region of an adult male. The antenna was kept at a distance of $5 \mathrm{~mm}$ from the body surface using a small piece of dielectric spacer (Rohacell HF 51 foam, $\varepsilon_{r}=1.07$ ) to inhibit direct loading caused by contact with wearer's skin.

The measurement environment considered in this study is described in [2]. As shown in Fig. 1 it consisted of a hallway which opened on to an office area. As well as containing furniture and equipment, the office was occupied for the duration of the experiments. A range of different off-body communications scenarios were considered. These included: 1) walking LOS - where the test subject stood in LOS at a distance of $25 \mathrm{~m}$ from the receiver setup, and then walked at a normal pace $\left(\sim 1.2 \mathrm{~ms}^{-1}\right)$ until he reached the point $1 \mathrm{~m}$ from the receiver setup before turning and walking in 2) NLOS to a point $25 \mathrm{~m}$ away; 3) walking LOS and 4) NLOS with pedestrian traffic- where the test subject repeated the LOS and NLOS measurements except this time a pedestrian walked in the opposite direction - scenarios 1-4 were repeated 4 times; 5) random movements - which considered the test subject walking randomly around the open office and hallway areas, including stopping to talk to other persons for 196 seconds.

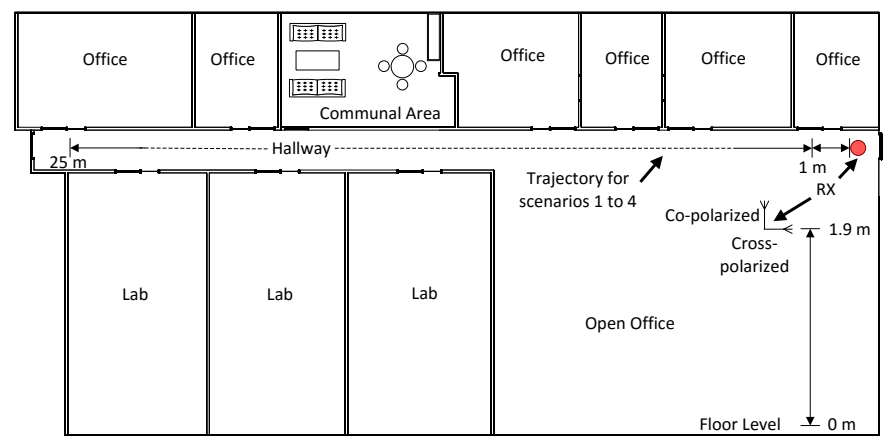

Fig. 1 Floor plan of measurement environment showing trajectories for scenarios 1 to 4 as well as the receive antenna configuration. 


\section{RESUlTS}

Fig. 2(a) shows the simultaneously sampled received signal power time series for the co- and cross-polarized receive antennas for trial 3 of scenario 1. Also shown for comparison is a log-distance path loss model fitted to the data by translating time to distance based upon an estimate of the test subject's walking speed. Table I shows the mean estimated parameters for the path loss exponent, $n$, and the power received at the reference distance of $1 \mathrm{~m}, P\left(d_{0}\right)$, averaged over all of the trials of each scenario. For convenience, the TX power level has been removed from the results so that they are all now referenced from $0 \mathrm{dBm}$.

One observation that becomes immediately apparent from the estimated path loss exponent is the very low values of $n$ obtained. This can be attributed to two separate propagation phenomena namely the waveguide effect caused by the hallway and the high metallic content of the ceiling and floors making the radio environment quite reverberant. These effects can be observed from Fig. 2(a) were the received signal power estimated by the path loss models are seen to decay slowly while over very short distances the received signal power is subject to significant fluctuation caused by multipath.

A slower varying trend can also be observed to impact the local mean signal level caused by the characteristics of the local environment and the test subject's movement. To abstract the slow fading process from the data, the estimated received signal power based upon the path loss models was first removed from the measurements. A moving average filter with a window size of 70 samples $(0.5 \mathrm{sec})$ was then applied to the resultant data. The slow fading was modeled using the lognormal distribution $[L \sim(\mu, \sigma)]$ commonly used to model shadowing processes. To obtain the small-scale fading process, both the estimated received signal power and the slow fading were removed from the measurement data. The small-scale fading component of the received signal is modeled using the Rice fading model [6], parameterized using $K$ and $\Omega$ [i.e. $R \sim(K, \Omega)]$, where $K$ is the Rice factor and $\Omega$ is the mean power.

For the LOS measurements of scenario 1 , the mean $K$ parameters obtained suggest that even for the cross-polarized channel, a dominant signal component exists. For the equivalent NLOS measurements (scenario 2), the $K$ parameter was significantly reduced, especially for the cross-polarized channel were the fading observed was close to that encountered in Rayleigh fading. For scenarios 3 and 4, the introduction of a mobile pedestrian moving in the opposite direction to the test subject had a noticeable effect on the $K$ values which were lower than those obtained for scenarios 1 and 2 respectively. For the random movements, the estimated $K$ values were comparable to those for scenario 1 . A simulation model for generating first-order received signal power for the co- and cross-polarized channels using the estimated parameters in Table I is provided in (1)

$$
P_{R X}(\mathrm{dBm})=P\left(d_{0}\right)+10 n \log _{10}\left(d / d_{0}\right)+20 \log _{10}(L \cdot R) .
$$

Figs. 2(b)-(d) show the good agreement between the measurements and data generated by (1) for a selection of trials. Note that all of the simulated data sets contained the same number of samples as the respective measurement trials.

\section{CONCLUSIONS}

Off-body communications at $5.8 \mathrm{GHz}$ within an indoor environment have been investigated. A statistical model for generating the first order received signal power characteristics based on the measurements has been presented and shown to provide a good match to the measured data.

\section{REFERENCES}

[1] S. L. Cotton, W. G. Scanlon \& P. S. Hall, "A simulated study of cochannel inter-BAN interference at $2.45 \mathrm{GHz}$ and $60 \mathrm{GHz}$," 3 rd EU Conf. on Wireless Technology (EuWiT), Paris, France, pp. 61-64, Sept. 2010.

[2] S. L. Cotton \& W.G. Scanlon, "Characterization and modeling of the indoor radio channel at $868 \mathrm{MHz}$ for a mobile bodyworn wireless personal area network," IEEE AWPL, vol. 6, pp. 51-55, 2007.

[3] R. Rosini, \& R. D'Errico, "Off-Body channel modelling at $2.45 \mathrm{GHz}$ for two different antennas," EUCAP 2012, pp.3378-3382, March 2012.

[4] P. Van Torre et al., "Characterization of Measured Indoor Off-Body MIMO Channels with Correlated Fading, Correlated Shadowing and Constant Path Loss," IEEE Tranactionss on Wireless Comms, vol.11, no.2, pp.712-721, February 2012.

[5] M. M. Khan et al., "Ultra wideband off-body radio channel characterisation and modelling for healthcare applications," Wireless Telecommunications Symposium (WTS), 2012, pp.1-5, 18-20 April 2012

[6] A. Abdi et al., "On the estimation of the $K$ parameter for the Rice fading distribution," IEEE Comms Ltrs, vol. 5, no. 3, p. 92-93, March 2001.
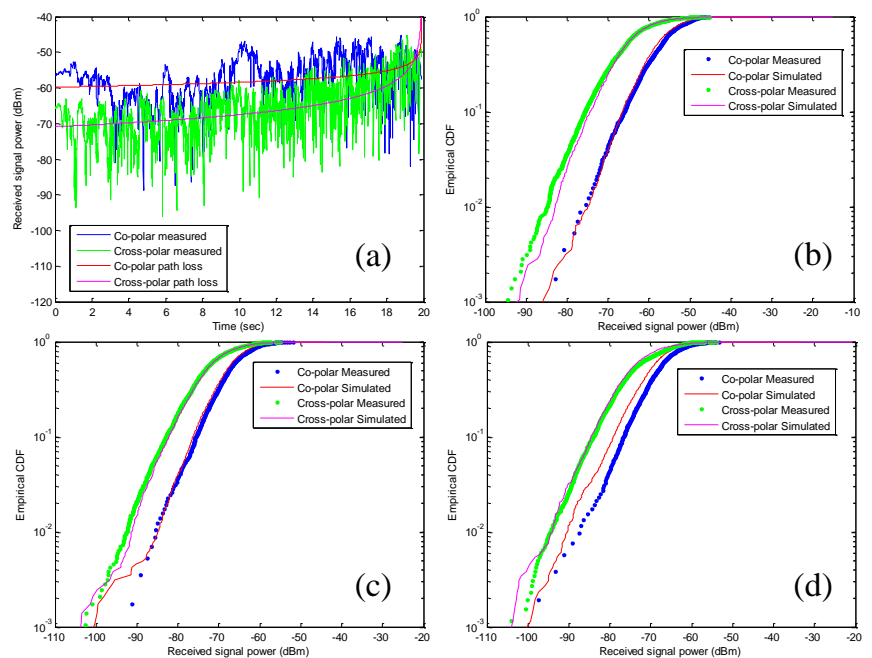

Fig. 2 (a) Co- and cross-polar received signal power time series and estimated RX power for trial 3 of scenario 1. Simulations for (b) trial 3, scenario 1, (c) trial 4, scenario 2 and (d) trial 2, scenario 4 (less satisfactory fit for co-polar).

\begin{tabular}{|c|c|c|c|c|c|c|c|c|c|c|c|c|}
\hline \multirow{2}{*}{ Scenario } & $\bar{n}_{c o}$ & $\bar{P}_{c o}\left(d_{0}\right)[\mathrm{dBm}]$ & $\bar{n}_{c p}$ & $\bar{P}_{c p}\left(d_{0}\right)[\mathrm{dBm}]$ & $\bar{\mu}_{c o}$ & $\bar{\sigma}_{c o}$ & $\bar{\mu}_{c p}$ & $\bar{\sigma}_{c p}$ & $\bar{K}_{c o}$ & $\bar{\Omega}_{c o}$ & $\bar{K}_{c p}$ & $\bar{\Omega}_{c p}$ \\
\hline 1 & -0.48 & -37.19 & -1.14 & -15.15 & 0.10 & 0.55 & 0.13 & 0.36 & 2.76 & 1.11 & 1.15 & 1.20 \\
\hline 2 & -0.68 & -38.47 & -1.05 & -26.96 & 0.13 & 0.36 & 0.16 & 0.34 & 1.25 & 1.19 & 0.50 & 1.25 \\
\hline 3 & -0.19 & -51.91 & -0.78 & -33.63 & 0.13 & 0.39 & 0.16 & 0.33 & 1.71 & 1.19 & 0.62 & 1.24 \\
\hline 4 & -0.74 & -37.52 & -1.13 & -25.07 & 0.15 & 0.33 & 0.16 & 0.36 & 1.10 & 1.23 & 0.36 & 1.26 \\
\hline 5 & - & - & - & - & -0.86 & 0.61 & -1.15 & 0.54 & 2.55 & 1.12 & 2.07 & 1.14 \\
\hline
\end{tabular}

